Railway Engineering

Jan. 2021

Issue:13, Page: 122-133

Research Article

doi: 10.47072/demiryolu. 826780

http://dergipark.org.tr/demiryolu

e-ISSN: 2687-2463, ISSN: 2149-1607

\title{
Lokomotif Çekerleri Hesaplama Yöntemi
}

\author{
Hüseyin Eren BENI $\odot$ \\ TCDD Genel Müdürlü̆̈ü, Kapasite Yönetim Dairesi Başk., Kapasite Geliştirme Şube Müd., \\ Ankara, Türkiye
}

h.erenbeni@hotmail.com

(Alını̧̧/Received: 16.11.2020, Kabul/Accepted: 09.12.2020, Yayımlama/Published: 31.01.2021)

Öz: Bu çalışmada genel olarak demiryolu hatlarında trene etki eden dinamik kuvvetler anlatılmıştır. Trenlerin seyir dirençleri lokomotif ve vagonlar olmak üzere iki ana faktör üzerinde incelenerek demiryollarında kullanılan formüllerden bahsedilmiştir. Aynı şekilde hat üzerinden gelen kurp ve rampa dirençlerinin trenler üzerinde etkisini gösteren Uluslararası formüllerden bahsedilmiştir. Daha sonra, trene etki eden dirençlerin yenilebilmesi için gerekli olan tekerlek kuvvetinin nasıl hesaplanacağına değinilmiştir. Tüm bu dirençler anlatıldıktan sonra lokomotifin çekebileceği yükün nasıl hesaplanacağı anlatılarak bazı firmaların hesapladığı lokomotif çekerlerinin karşılaştırılması yapılarak hangi formüllerin kullanılmasının faydalı olacağı değerlendirilmiştir.

Anahtar kelimeler: Tren Direnci, Seyir Direnci, Lokomotif, Çeker

\section{Locomotive Tractive Calculation Method}

Abstract: In this study, dynamic forces that affect train on railway lines are explained in general. running resistances of trains are analysed on two factors as locomotive and wagons and the formulas used in developed countries for railways are mentioned. Likewise, international formulas that show the effect of the curve and ramp resistances coming from the line on trains are mentioned. Later on, mentioned on how to calculate the needed wheel force to overcome the resistances that affect the train. After all these resistances are explained, the calculation of tractive force of the locomotive is clarified and it is explained that which formulas would be beneficial by comparing locomotive tractions in some companies.

Keywords: Train Resistance, Running Resistance, Locomotive, Haulage

\section{Giriş}

Ülkemizde taşımacılığın sürekli geliştiği bu dönemde taşımacılık açısından demiryollarına talepte her geçen gün artmaktadır. Bu talebin karşılanması için demiryollarında taşıma kapasitesi açısından güçlü bir demiryolu ağına sahip olunması gerekmektedir. Ülkemizin coğrafik konumu nedeniyle eğimli arazilerimiz dolayısıyla eğimli demiryolu hatlarımız mevcuttur. Bu eğimli hatlar lokomotifin çekme kapasitesini oldukça etkilemektedir.

Lokomotifin çekme kapasitesini birçok faktör etki etmektedir. Hareket ettirilmek istenen bir tren; harekete karşı koyan bir dizi sınırlamalar ve etkenlerle karşı karşıya kalır. Trenin hareketinin sağlanmasında ve seyrinde istenilen hızlara ulaşmak, istenilen yükleri çekmek ve istenilen güçlere çıkmak her zaman mümkün olmamaktadır. Bu nedenle trene etki eden dirençleri yenebilecek tekerlek kuvvetinin sağlandığı güç kadar lokomotifler yük çekebilecektir.

Bu çalışmada, lokomotif ve vagonlara etki eden dirençler incelenmiştir. Bu kapsamda uluslararası kabul edilen bazı formüller ve formüllerde hangi parametrelerin dikkate alındığı gösterilmiştir. Yapılan çalışmada lokomotiflerin çekme kapasitesinin ideale yakın şekilde hesaplanması ve formüllerin birbiri ile kıyaslanarak hangi formülün çekme kapasitesine nasıl etki ettiğinin belirlenmesi amaçlanmaktadır. 


\section{Metot}

Demiryollarının yük taşımacılığındaki öneminin artması ile birlikte lokomotiflerin ne kadar yük çekebileceğinin doğru bir şekilde hesaplanması gerekliliği doğmuştur. Pek çok önde gelen ülke demiryollarındaki trenin çekme kapasitesini belirlemek için geliştirdikleri formüller ve yöntemler vardir.

Trenitalia ve SNCF firmasının kullanmış olduğu tüm direnç formüller belirtilmiştir. Söz konusu direnç formüllerin yenilebilmesi için gerekli tekerlek kuvvetinin hesabının nasıl yapılacağı açıklanmıştır. Lokomotif çekerleri doğru bir şekilde kıyaslayabilmek için örnek bir dizel örnek bir lokomotif ile her bir rampa değerinde çekebileceği tonajlar hesaplanarak karşılaştırılmıştır.

\subsection{Tren hareketi}

Trenin hareketini etkileyen unsurlar;

Trenin hareketine karşı koyan ve trenin V sabit hızı ile seyretmesine engel olan zıt kuvvetler (dirençler),

$>$ Dirençleri yenecek cer kuvveti ile kalkışta aderansın getirdiği sınırlamalar,

$>$ Lokomotif güçleri ve bu güçlerin tekerleklere aktarılması esnasındaki kayıplar,

$>$ Cer kuvvetine gelen sinırlamalar,

$>$ Kanca mukavemetinden gelen sinırlamalardır [1].

Trenin hareket edebilmesi için yenmesi gereken dirençler aşağıda belirtilmiştir;

$>$ Lokomotif Seyir Direnci RL,

$>$ Vagon Seyir Direnci $R_{\mathrm{V}}$,

$>$ Kurp Direnci $\mathrm{R}_{\mathrm{k}}$,

$>$ Rampa Dinenci $\mathrm{R}_{\mathrm{r}}$,

$>$ Akselerasyon Direnci $\mathrm{R}_{\mathrm{a}}[1]$.

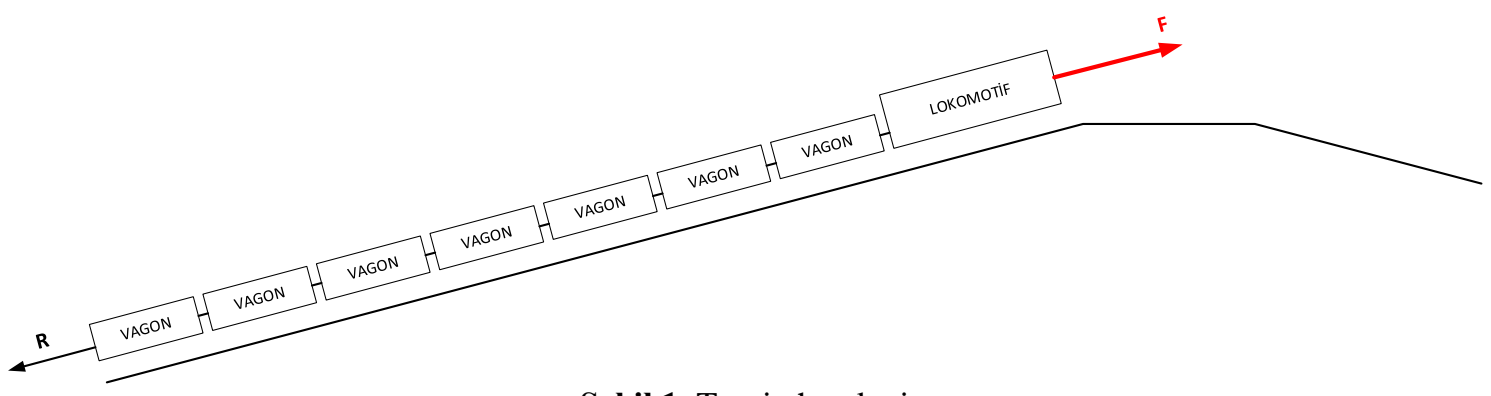

Şekil 1. Trenin hareketi

Trenlerin hareket edebilmesi için yukarıdaki dirençleri yenmesi gerekmektedir. Bu dirençlerin toplamı; $\mathrm{R}=\mathrm{R}_{\mathrm{L}}+\mathrm{R}_{\mathrm{V}}+\mathrm{R}_{\mathrm{r}}+\mathrm{R}_{\mathrm{k}}$ olarak ifade edilir. Lokomotifin cer gücü toplam direnci yenmesi halinde duran bir trenin hareketi, hareket ediyorsa hızlanabilmesi sağlanır. Lokomotifin çekme kuvvetine (cer gücüne) F dersek;

$\mathrm{R}>\mathrm{F} \quad$ ise trenin hareketi sağlanamaz veya hareket halinde ise yavaşlar ve durur.

$\mathrm{R}=\mathrm{F}$ ise hareket halindeki bir tren belirli bir $\mathrm{V}$ hizı ile seyrine devam eder.

$\mathrm{R}<\mathrm{F}$ ise hareket sağlandığı gibi aynı zamanda tekerlek kuvveti-direnç farkı $(\mathrm{F}-\mathrm{R})$ kadar olan kuvvet farkından dolayı bir ivme (akselerasyon) kazanır. Yani tren gittikçe hızlanır [1]. 


\subsection{Tren direnci}

Tren direnci trenin hareketine zit yönde etki eden dirençlerdir. Harekete karşı koyan dirençler, genel olarak Şekil 2.'de görüldüğü gibi hıza bağlı olmakla birlikte hızdan başka; lokomotiflerin tipine, tekerlek ile ray arasındaki sürtünmelere, dingil başlarının (muyluların) dingil kutusu içerisinde sürtünmesine, hava direncine, hat ile araçların bakım koşullarına, hattın teknik özelliklerine ve rayların kalitesine bağlıdır.

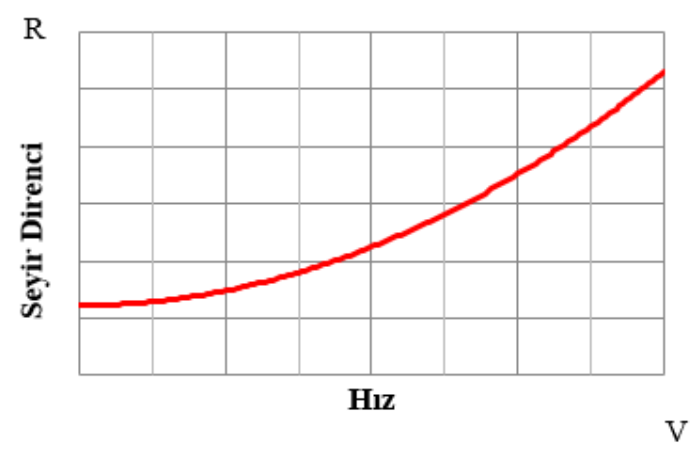

Şekil 2. Hızın seyir direncine olan etkisi

Demiryollarında tren direnci ile ilgili çalışmalar incelendiğinde deneysel verilere dayalı tren direnci ile ilgili formülleri ilk olarak Schmidt (1910) tarafından yayınlanmıştır ve geliştirilmiştir. [2-4]. Daha sonraki zamanlarda formüller Strahl (1913) ve Davis (1926) tarafindan geliştirilmiştir. Deneysel çalışmalar sonucunda Tren direnci hıza bağlı ikinci derece bir fonksiyonla ifade edilmektedir. Aşağıdaki eşitliğe genel olarak Davis eşitliği denilmektedir. Literatürde bu eşitliğe; von Borries Formel, Leitzmann Formel, Barbier eşitliği de denilmektedir $[5]$.

$$
\mathrm{R}=\mathrm{A}+\mathrm{B} \times \mathrm{V}+\mathrm{C} \times \mathrm{V}^{2}
$$

Yukarıdaki eşitlikte; V tren hızını göstermekte ve birimi m/s dir. A, B, C ampirik katsayılardır ve birimleri sırasıyla $\mathrm{N}, \mathrm{Ns} / \mathrm{m}$ ve $\mathrm{Ns}^{2} / \mathrm{m}^{2}$ dir. A, B ve C katsayıları; hıza, dingil basıncina, dingil ve aks sayısına, vagon sayısına, tren uzunluğuna, yol tipine, lokomotif tipine göre belirlenmektedir [5].

İlk terim olan A mekanik direnci ifade eder; hızdan bağımsızdır, dingil basıncı, dingil ve aks sayısı, tren uzunluğu, araç tipi, yol tipi ile değişmektedir. A terimi özellikle dingil basıncı ve dingi sayısı ile lineer olarak artmaktadır. A terimi yani mekanik direnç, dingil ve aks kutusu içindeki yataklardaki rulmanların direncini ve tekerlek ile ray arasındaki temas nedeniyle meydana gelen sürtünmeyi ifade eder [5].

İkinci terim BV, amprik B katsayısı ve hız ile değişmektedir. B katsayısı; tren uzunluğu veya dingil ve aks sayısı gibi boyutsal etkiler ile değişmekte olup dingil basıncının etkisini içermemektedir. Dingil basıncının etkisinin olmaması, BV teriminde mekanik direncin olmadığ 1 anlamına gelmektedir. BV terimi üçüncü terimle ifade edilen hava direncinin bir bölümünü de içerir. Tren yükünden ziyade uzunluğunun bir fonksiyonudur [5].

Üçüncü terim olan $\mathrm{CV}^{2}, \mathrm{C}$ katsayısı ve hızın karesi ile değişmektedir. $\mathrm{CV}^{2}$ terimi lokomotifin ve vagonların ön ve arka alanına etki eden aerodinamik dirençleri ve trenin uzunluğu ile lineer olarak artan aerodinamik dirençlerin toplamını ifade eder [5]. 


\subsection{Lokomotif seyir (çeken aracın) direnci}

Lokomotif seyir direncini $\left(\mathrm{R}_{\mathrm{L}}\right)$ etkileyen unsurlar;

Lokomotifin ağırlı̆̆ 1

$>$ Lokomotifin dingil sayıs

> Dingil başlarının (muyluların) dingil kutusu içinde sürtünmesi (muylu direnci)

$>$ Tekerlek ray arasındaki sürtünme direnci

$>$ Lase hareketleri (mekanik hareketlilik ile yatay ve dikey titreşimler)

$>$ Lokomotifin ön yüzüne dikey doğrultuda etki eden hava direnci (rüzgar direnci).

Lokomotif seyir direnci için deneysel olarak belirlenmiş birçok formül mevcuttur;

Her tip çeken ve çekilen araca uygulanabilen 1926 yılında Davis tarafından bulunan formüldür. $[6]$.

$$
\begin{gathered}
r_{\mathrm{s}}=0,65+\frac{13,13}{\mathrm{p}}+0,00932 \times \mathrm{V}+\frac{0,004526}{\mathrm{p} \times \mathrm{n}} \times \mathrm{A} \times \mathrm{V}^{2} \\
\mathrm{R}_{\mathrm{S}}=\mathrm{r}_{\mathrm{s}} \times \mathrm{G}
\end{gathered}
$$

$\mathrm{Bu}$ formüllerde;

- $\mathrm{V}=$ Aracın hizı $(\mathrm{km} / \mathrm{h})$

- $\quad \mathrm{p}=$ Aracın dingil yükü (ton)

- $\mathrm{n}=$ Aracin dingil sayıs1

- $\mathrm{A}=$ Aracin ön yüzey alanı

- $\mathrm{G}=$ Aracın ağırlı̆̆ 1

- $r_{\mathrm{s}}=$ Bir tona etki eden seyir direnci (daN/ton)

- $\mathrm{R}_{\mathrm{S}}=$ Aracin seyir direnci $(\mathrm{daN})$ ifade eder [7].

Standart hat olarak tanımlanan $1435 \mathrm{~mm}$ 'lik hatlarda, araçların ön yüzey alanlarıA $\approx 10,5 \mathrm{~m}^{2}$ dir. Fransız Demiryolları SNCF, Davis formülünü bu değerlere uygulamış ve aşağıdaki şekilde geliştirmiştir.

$$
\mathrm{R}_{\mathrm{L}}=0,65 \times \mathrm{G}_{\mathrm{L}}+13 \times \mathrm{n}+0,01 \times \mathrm{G}_{\mathrm{L}} \times \mathrm{V}+0,045 \times \mathrm{V}^{2}
$$

$\mathrm{Bu}$ formülde;

- $\quad \mathrm{V}=\operatorname{Aracin} \operatorname{hizl}(\mathrm{km} / \mathrm{h})$

- $\mathrm{n}=$ Aracin dingil sayıs1

- $\mathrm{G}_{\mathrm{L}}=$ Lokomotifin ağırlığı (ton)

- $\mathrm{R}_{\mathrm{L}}=$ Lokomotifin seyir direnci (daN) ifade eder [7].

Ayrıca lokomotif seyir direnç formülleri için lokomotifi üreten firmaların deney ve testler sonucu bulduğu formüller de kullanılabilir.

\subsection{Vagon seyir (çekilen aracın) direnci}

Vagon seyir dirençlerini etkileyen faktörler;

$>$ Vagonun ağırlı̆ 1

$>$ Vagonun dingil sayıs1 
Dingil başlarının dingil kutusu içinde sürtünmesi (muylu direnci)

$>$ Tekerlek ray arasındaki sürtünme direnci

$>$ Lase hareketleri (mekanik hareketlilik ile yatay ve dikey titreşimler) [7].

Vagon seyir dirençleri hesaplanırken birim olarak 1 (ton) vagon yüküne göre seyir direnci hesaplanır ve bu $\mathrm{r}_{\mathrm{vs}}$ ile gösterilir. Vagon ağırlıkları $\mathrm{G}_{\mathrm{V}}($ ton) olduğundan, vagonların seyir direnci;

$$
\mathrm{Rv}=\mathrm{r}_{\mathrm{vs}} \times \mathrm{G}_{\mathrm{V}}(\mathrm{daN})
$$

olarak bulunur.

Fransız Demiryolları (SNCF) çeşitli vagonlar için aşağıdaki formülleri kullanmaktadır;

Ağırlığı 41-46 ton arasında olan bojili yolcu vagonları;

$$
r_{v s}=1,5+\frac{v^{2}}{4500}(\text { daN/ton })
$$

Ağırlığı 46-56 ton arasında olan bojili yolcu vagonları;

$$
\mathrm{r}_{\mathrm{vs}}=1,25+\frac{\mathrm{V}^{2}}{6300}(\mathrm{daN} / \text { ton })
$$

Hızı $100 \mathrm{~km} / \mathrm{h}$ olan ve tamamı aynı tip kapalı vagonlardan oluşan yük trenleri;

$$
r_{v s}=1,5+\frac{V^{2}}{4200}(\mathrm{daN} / \text { ton })
$$

Yükü ve darası toplamı 80 ton olan spesifik vagonlar;

olarak ifade edilir [7].

$$
\mathrm{r}_{\mathrm{vs}}=1,2+\frac{\mathrm{V}^{2}}{4500}(\mathrm{daN} / \mathrm{ton})
$$

Alman demiryolları (DB) aşağıdaki formülleri kullanmaktadır;

Ağırlığı 40-45 ton arasında olan bojili yolcu vagonları;

$$
\mathrm{r}_{\mathrm{vs}}=1,8+\frac{\mathrm{V}^{2}}{3500}(\mathrm{daN} / \text { ton })
$$

Yük vagonlar1;

$$
\mathrm{r}_{\mathrm{vs}}=1,5+\frac{\mathrm{V}^{2}}{1200}(\mathrm{daN} / \mathrm{ton})
$$

Strahl formülü aşağıdaki şekilde kullanmaktadır;

$$
r_{\mathrm{vs}}=2+0,057 \times \frac{\mathrm{V}^{2}}{100}(\mathrm{daN} / \text { ton })
$$

olarak ifade edilir [8]. 


\subsection{Trenitalia firmasının tren dizileri için kullandı̆̆ı seyir direnci}

Yük ve yolcu trenlerinin seyir direncinin hesaplamasında Trenitalia'nın kullandığ formüller deneysel yöntemlerle bulunmuştur.

Yük treni seyir direnci;

$$
r=1,5+0,00064 \times v^{2}
$$

Yolcu treni seyir direnci;

$$
r=1,3+0,000162 \times v^{2}
$$

$\mathrm{Bu}$ formüllerde;

- $\mathrm{V}=\mathrm{Aracin} \operatorname{hizl}(\mathrm{km} / \mathrm{h})$

- $\quad r=$ Tren dizisinin direnci (daN/ton) ifade eder.

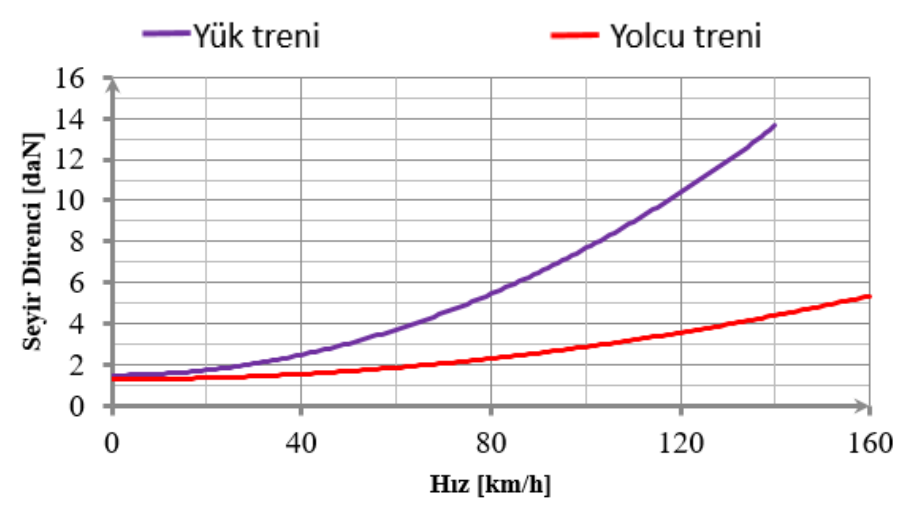

Şekil 3. Yük ile yolcu trenlerinin seyir dirençlerinin karşılaştırması

(13) ve (14) numara ile verilen formüllere göre yük ve yolcu trenlerinin seyir dirençlerinin karşılaştırılması Şekil 3.'te gösterilmiştir.

\subsection{Kurp (viraj) direnci}

Kurp Direnci trenin kurptan geçerken lokomotifin aşması gereken ilave dirençtir. Demiryolu güzergâhının coğrafik ve geometrik koşulları nedeniyle oluşan kurplar trenin hareketini olumsuz yönde etkiler. Bu olumsuzlukları azaltmak ve trenin hareketi esnasında $\mathrm{V}$ hızına bağlı olarak meydana gelen merkezkaç kuvvetini dengelemek için yola dever verilmektedir. Ülkemizde maksimum 130 mm'ye kadar dever uygulanmaktadır [7].

Trenlerin verilen dever ölçüsüne göre hesaplanan hızlarda seyretmesi gerekir. Verilen dever hızına uygun hızlarda seyredilmemesi hâllerinde tekerlek bodenleri raya yaslanır ve bir direnç oluşur. Dever ölçüsüne uygun hızlarda kurptan geçilmediğinde oluşan bu dirençler tekerlek bodenlerini ve rayı aşındıran bir faktör olarak karşımıza çıkmaktadır. Kurp üzerindeki trenin direncini hesaplamak için uluslararası kabul edilen aşağıdaki formüller kullanılmaktadır [7].

Protopapadakis formülü aşağıdaki şekilde kullanmaktadır;

Ekartman açıklığı 1435 mm lik hatlarda; 
Yaz mevsimi için;

$$
\mathrm{r}_{\mathrm{k}}=\frac{232,2+103,4 \times \mathrm{a}}{\rho}
$$

Kış mevsimi için;

$$
\mathrm{r}_{\mathrm{k}}=\frac{175+77,6 \times \mathrm{a}}{\rho}
$$

$\mathrm{Bu}$ formüllerde;

- $\mathrm{r}_{\mathrm{k}}$ : Birim kurp direnci (daN/ton)

- $\rho:$ Kurp yarıçapı (m)

- $\quad \mathrm{a}$ : Dingiller aras1 rijit uzunluk (m) ifade eder. [7].

Röckl formülü aşağıdaki şekilde kullanmaktadır;

Alman demiryolları Deutche Bahn tarafından aşağıdaki formül kullanmaktadır.

Ekartman açıklı̆̆ı 1435 mm lik hatlarda;

$$
r_{k}=\frac{650}{\rho-55}(\text { daN/ton })
$$

SNCF formülü aşağıdaki şekilde kullanmaktadır;

$$
\mathrm{r}_{\mathrm{k}}=\frac{800}{\rho}(\mathrm{daN} / \text { ton })
$$

Trenitalia demiryolları tarafından da SNCF formülü kullanılmaktadır. Birim tona etki eden kurp direnci $\mathrm{r}_{\mathrm{k}}$ 'dir. Kurp üzerindeki trenin direnci;

$$
\mathrm{R}_{\mathrm{k}}=\mathrm{r}_{\mathrm{k}} \times\left(\mathrm{G}_{\mathrm{V}}+\mathrm{G}_{\mathrm{L}}\right)(\mathrm{daN})
$$

olarak ifade edilir [9].

\section{7. Ĕ̈im (rampa) direnci}

Hattın eğimi (rampalar) demiryollarında binde olarak gösterilir. Rampa direnci hat üzerinde yukarı yönlü eğimin üstesinden gelme kuvvetidir. Hızdan bağımsızdır.

Rampa üzerinde etki eden tren direnç için Uluslararası alanda aşağıdaki formüller çok yaygın olarak kullanılır;

$$
\begin{gathered}
\mathrm{R}_{\mathrm{r}}=\mathrm{r}_{\mathrm{r}} \times\left(\mathrm{G}_{\mathrm{V}}+\mathrm{G}_{\mathrm{L}}\right) \\
\mathrm{r}_{\mathrm{r}}=\mathrm{i}
\end{gathered}
$$

$\mathrm{Bu}$ formüllerde;

- $\quad \mathrm{i}=$ Hattın eğimi 
- $\mathrm{r}_{\mathrm{r}}=$ Rampa birim direnci (daN/ton)

- $\mathrm{R}_{\mathrm{r}}=$ Rampa direnci (daN) ifade eder.

\subsection{Tekerlek kuvveti hesabt}

Tekerlek kuvveti lokomotifin aracın tahrikli tekerleklerinin tamamındaki çekme kuvvetini ifade eder.

$$
\mathrm{P}=(\mathrm{F} \times \mathrm{V}) / 360(\mathrm{~kW})
$$

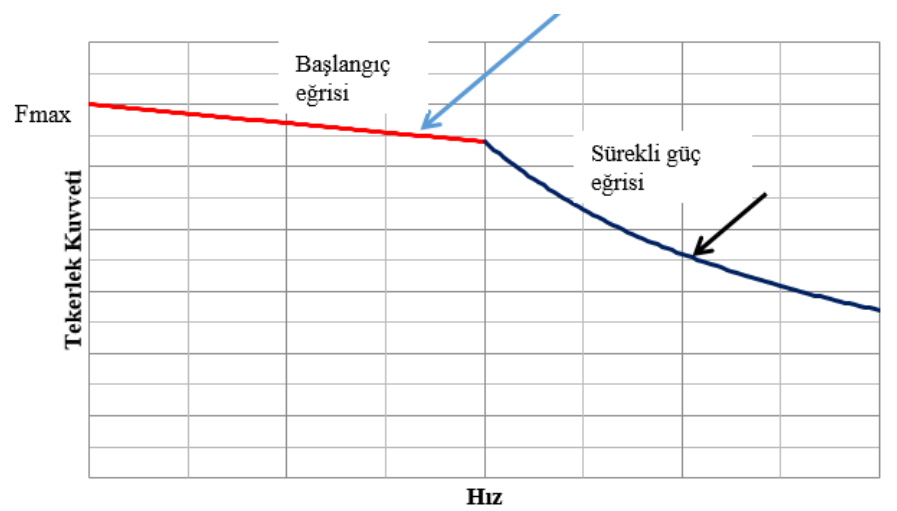

Şekil 4. Elektrikli lokomotifteki tekerlek kuvvetinin hız ile değişimi

Tahrikli kuvvetin tekerleklere uygulanması gereken güçte lokomotifin gücü olup, $\mathrm{P}$ ile gösterilmiştir. Lokomotifin tekerlek kuvveti F (daN), lokomotifin hızı V (km/s) olarak tanımlanır. Örnek olarak verilen dizel ve elektrikli lokomotiflerin güç eğrileri şekil 4. ve 5'te gösterildiği gibi iki bölgeyi gösterir;

$>$ Başlangıç eğrisi

$>$ Sürekli güç eğrisi

Başlangıç aşamasında maksimum çekiş gücü motorların sürtünme ve maksimum sürüş torku ile sınırlıdır. Bu aşamada lokomotifler sadece sınırlı bir süre boyunca çalışabilir. Sürekli güç aşamasında ise sınır lokomotifin kendi gücü ile sınırlıdır. Lokomotif bu bölgede eğri üzerindeki kuvvetle zaman sınırı olmadan çalışabilir. Başlangıç eğrileri elektrikli lokomotiflerde dizellere oranla daha yüksek hızlara ulaşabilmektedir.

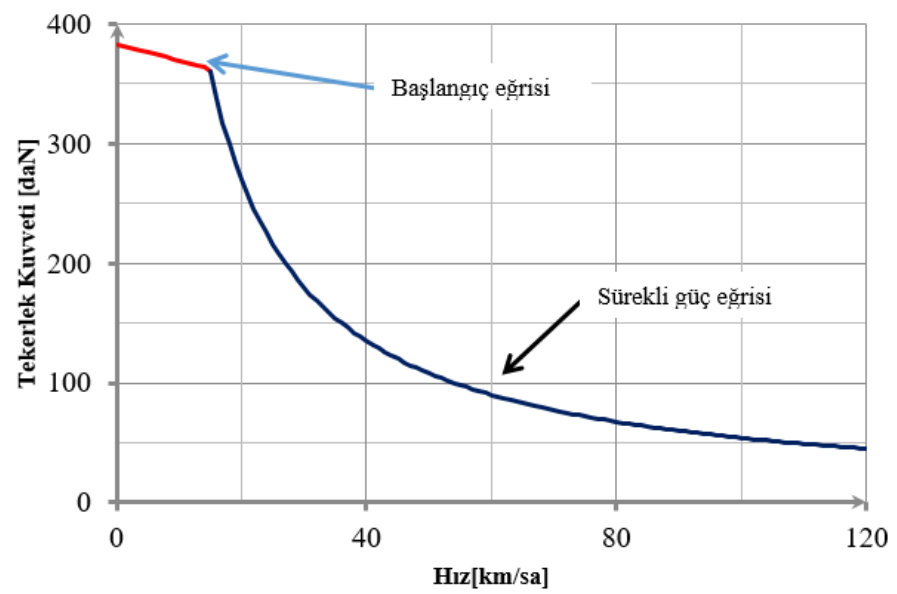

Şekil 5. Dizel lokomotifteki tekerlek kuvvetinin hız ile olan değişimi 
Bir hattın ortalama eğim hesabı yapılırken o hatta çalışan en uzun trenin uzunluğu içinde kalan değerler dikkate alınır. Bu değerlerin ortalaması alınarak ortalama eğim bulunur.

\section{9. Çekilebilecek yük hesabı}

Lokomotifin çekeceği yük, arkasına bağlı olan vagonların ağırlığının toplamıdır. Bu kapsamda lokomotifin çekeceği yük aşağıdaki parametrelere bağlıdır;

$>$ Trenin hizına,

Kurp ve rampa direncine,

$>$ Lokomotif ve vagonların direncine,

$>$ Koşum takımlarının mukavemetinden gelen sınırlamalara,

$>$ Aderansın getirdiği sinırlamalara,

> Tekerlek kuvvetine dolayısıyla tekerlek gücüne,

Bağlı olup, her lokomotif tipine göre çekilecek yükler farklı olarak hesaplanır.

Şekil 6.'da Örnek bir elektrikli ile dizel lokomotifin düz bir yolda ve 15 \% rampadaki direncin trenin hızına olan etkisini görüyoruz.

Trenlerin hareket edebilmesi için yukarıda formülleri verilen dirençleri yenmesi gerekmektedir. $\mathrm{Bu}$ dirençlerin toplamı;

$$
\mathrm{F}_{\mathrm{SÜR}}=\mathrm{R}_{\mathrm{L}}+\mathrm{R}_{\mathrm{V}}+\mathrm{R}_{\mathrm{r}}+\mathrm{R}_{\mathrm{k}}
$$

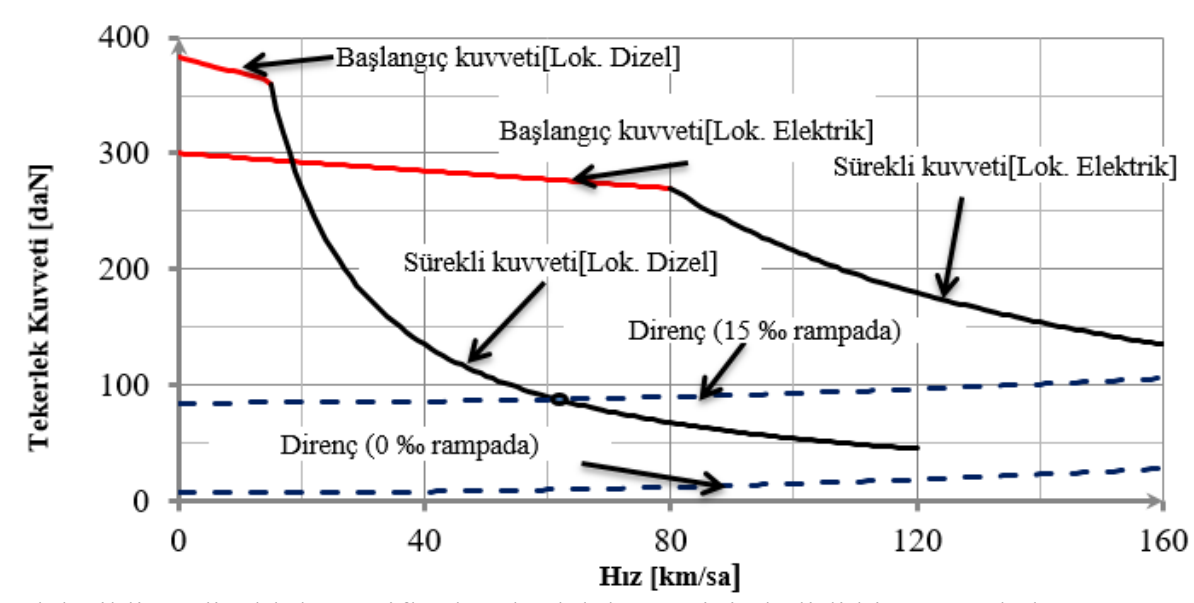

Şekil 6. Elektrikli ve dizel lokomotiflerde tekerlek kuvvetinin belirli bir rampada hıza olan durumunu gösteren grafik

Trenin çekebileceği yükü hesaplarken tekerlek kuvvetinin sürekli olmaya başladığı nokta seçilir. $\mathrm{Bu}$ noktada lokomotif eğrideki tekerlek kuvvetini sürekli olarak uygulayabilir. Başlangıç kuvvetinin olduğu eğrideki belirtilen tekerlek kuvveti o gücü sürekli olarak sağlayamaz. Demiryolları literatürlerinde kurp ve rampa direncinin toplamına eşdeğer direnç $\left(\mathrm{R}_{\mathrm{e}}\right)$ denmektedir. (23) numaralı denklemden çekilecek yük hesabı yapmak için;

$$
\mathrm{G}_{\mathrm{V}}=\frac{\mathrm{F}_{\mathrm{SÜR}}-\mathrm{R}_{\mathrm{L}}-\mathrm{r}_{\mathrm{e}} \times \mathrm{G}_{\mathrm{L}}}{\mathrm{r}_{\mathrm{V}}+\mathrm{r}_{\mathrm{e}}}
$$

denklemi elde edilir. 


\section{Bulgular}

Lokomotif çekeri için dirençleri hesaplarken lokomotife etki eden en büyük direnç, rampa direnci olmaktadır. Bu nedenle her eğimde lokomotifin ne kadar yük çekebileceğinin hesaplanması gerekmektedir. 129 ton ağırlığında, $2750 \mathrm{~kW}$ güce sahip ve sürekli kuvveti uygulayabildiği hızı $20 \mathrm{~km} / \mathrm{s}$ olan bir dizel lokomotifin ortalama yarıçapı 500 metre olan bir hatta çekebildiği yük aşağıdaki gibi olmaktadır.

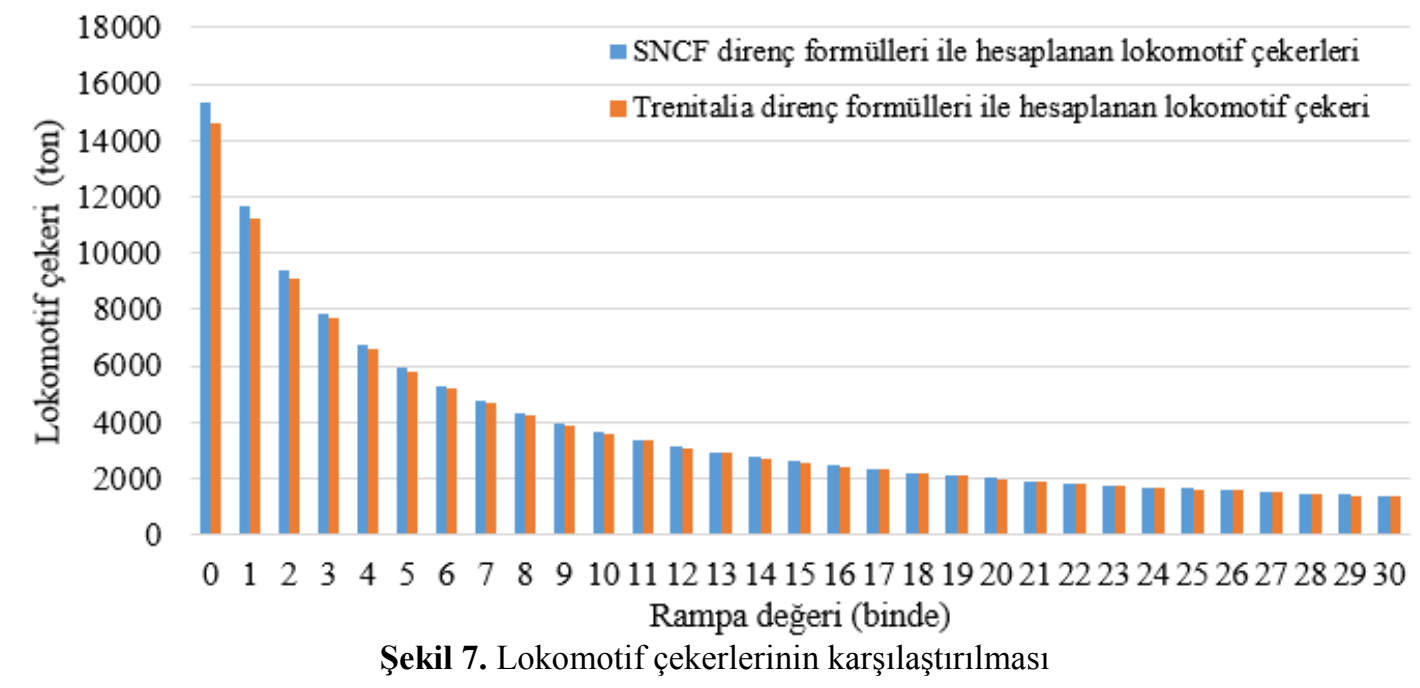

SNCF lokomotif seyir direnci için (4), vagon seyir direnci için (8) numaralı formüller kullanılmıştır. Şekil 7. ve Tablo 1. incelendiğinde direnç formüllerinin ampirik katsayıları ne kadar büyükse lokomotifin çekebileceği yük miktarının da düşeceğini gözlemlenir. Şekil 7. ve Tablo 1. İçin hesaplanan lokomotif çekerleri için düz olan yollarda veya rampadan inişlerde SNCF firmasının kullandığı yöntem ile lokomotiflerin daha fazla tonaj çekebileceği görülmektedir. Rampa değeri arttıkça firmalar arasında lokomotif çekerlerinin çekebileceği tonaj farkının kapandığı gözlemlenmektedir.

Tablo 1. Rampaya (eğime) göre hesaplanan lokomotif çekerleri

\begin{tabular}{ccc}
\hline $\begin{array}{c}\text { Rampa } \\
\text { (binde } \\
\text { değeri) }\end{array}$ & $\begin{array}{c}\text { SNCF direnç } \\
\text { formülleri ile } \\
\text { hesplanan lokomotif } \\
\text { çekerleri(ton) }\end{array}$ & $\begin{array}{c}\text { Trenitalia direnç } \\
\text { formülleri ile hesaplanan } \\
\text { lokomotif çekeri(ton) }\end{array}$ \\
\hline 0 & 15362 & 14621 \\
1 & 11670 & 11235 \\
2 & 9399 & 9113 \\
3 & 7861 & 7659 \\
4 & 6750 & 6600 \\
5 & 5911 & 5795 \\
6 & 5254 & 5162 \\
7 & 4726 & 4651 \\
8 & 4292 & 4230 \\
9 & 3930 & 3877 \\
10 & 3622 & 3577 \\
11 & 3358 & 3319 \\
12 & 3129 & 3094
\end{tabular}




\begin{tabular}{lll}
13 & 2927 & 2897 \\
14 & 2750 & 2723 \\
15 & 2591 & 2568 \\
16 & 2450 & 2428 \\
17 & 2322 & 2303 \\
18 & 2206 & 2189 \\
19 & 2101 & 2085 \\
20 & 2005 & 1990 \\
21 & 1917 & 1903 \\
22 & 1836 & 1823 \\
23 & 1761 & 1749 \\
24 & 1691 & 1680 \\
25 & 1627 & 1617 \\
26 & 1566 & 1557 \\
27 & 1510 & 1502 \\
28 & 1458 & 1450 \\
29 & 1408 & 1401 \\
30 & 1362 & 1355 \\
\hline
\end{tabular}

\section{Sonuç}

Türkiye'nin coğrafik konumu nedeniyle demiryolu hatları iniş ve çıkışları çok olan eğimli arazilerden geçmektedir. Bu eğimli araziler demiryolunda trenlerin çekme kapasitesini oldukça düşürmektedir. Ancak son zamanlarda demiryolu hat yapımlarında tünel, viyadük, köprü yapımlarının artması nedeniyle eğim oranı mümkün olduğunca düşük tutulmaktadır. Bu nedenle yeni hatlarda trenlerin çekme kapasitesi eski hatlara oranla daha yüksektir.

Günümüzde demiryollarında farklı güçte ve farklı kuvvetlerde birçok lokomotif bulunmaktadır. Gelişen teknoloji ile yeni lokomotiflerde tekerlek kuvveti artmış olup, çekme kapasitesi daha yüksektir. Lokomotiflerin çekebileceği yük hesaplanırken deneylerle elde edilmiş birçok formül bulunmaktadır. Bu formüllere göre lokomotifin çekebileceği yük miktarı değişkenlik gösterir.

Yapılan deneyler sonucu bulunan bu formüllerde ampirik katsayıların büyük olması durumunda dirençlerin büyük olacağından dolayı lokomotiflerin çekme kapasitesi düşük olacaktır. Trenitalia'nın deney ve testler sonucu bulmuş olduğu (13) ve (14) numaralı formülde tren uzunluğundan dolayı oluşabilecek dirençleri etkisinin çok az olması nedeniyle yok varsaymıştır. Ayrıca lokomotiflerin ve vagonların dirençlerini ayrı ayrı hesaplamak yerine trenlerin seyir dirençlerini hesaplayarak dirençlere etki edebilecek parametreleri azaltmışlardır.

$\mathrm{Bu}$ çalışmada lokomotif çekerleri ile ilgili SNCF ile Trenitalia firmalarının kullanmış olduğu direnç formüllerine değinilmiş olup, bu iki firma tarafından kullanılan lokomotif çekerlerinin karşılaştırılması yapılarak hangi eğimde hangi çeker formülünün avantajlı olduğu gözlemlenmiştir. Demiryollarında öncü birç̧ok Ülkenin kullanmakta olduğu direnç formüllerin, aderansın getirdiği sınırlamaların ve kanca çekerinden dolayı gelen sınırlamaların hesaplamalara katılması, bu çalışmanın içeriğini genişletebilir. 


\section{Kaynakça}

[1] Tren Dinamiği ve Tekerlek Kuvvetleri. Ankara, Turkey: Megep Yayınları, 2014.

[2] E. Schmidt, Freight train resistance: its relation to car weight. University of Illinois: Engineering Experiment Station, vol. 31, no. 48, 1910.

[3] E. C. Schmidt, F. W. Marquis, The effects of cold weather upon train resistance and tonnage rating. University of Illinois: Engineering Experiment Station, vol. 59. no. 25, 1912.

[4] E. Schmidt, Freight train curve resistance on a one-degree curve and on a three-degree curve. University of Illinois: Engineering Experiment Station, vol. no. 45, 1927.

[5] Ö. Akbayır, F. H. Çakır, "Enerji verimliliği için tren direnci formüllerinin karşılaştırılması," Mehmet Akif Ersoy Üniversitesi Fen Bilimleri Enstitüsü Dergisi, vol. 8, no. 1, pp. 112-126, 2017.

[6] W. J. Davis, The tractive resistance of electric locomotives and cars. Schenectady. N.Y.: General Electric, 1926.

[7] C. Urlu, Demiryolu araçlarının ileri dinamiği. Ankara, Turkey: TCDD Yayınları, 1999.

[8] G. Strahl, "Verfahren zur bestimmung der belastungsgrenzen der dampflokomotiven," Z. Des. Vereins Dtsch. Ing. vol. 57, pp. 251, 1913.

[9] S.Y. Sapronova, V.P. Tkachenko, O.V. Fomin, I.I. Kulbovskiy E.P. Zub, Rail vehicles: the resistance to the movement and the controllability. Duit state university of infrastructure and technology, 2017.

\section{Özgeçmiş}

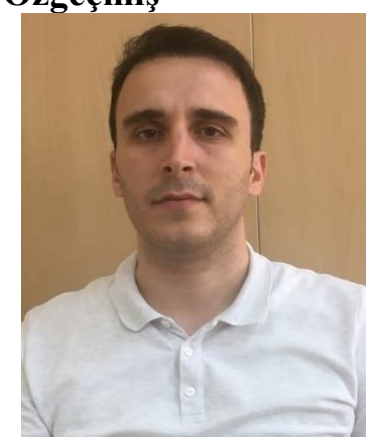

\section{Hüseyin Eren BENI}

1988 yılında Bursa'da doğdu. 2010 y1lında Dumlupınar Üniversitesi Makine Mühendisliği'ni bitirdi. INVENT TR firmasında beş ay kontrol mühendisi olarak görev yaptı. Almanca B2 sertifikasına sahiptir. 2014 Temmuz ayında 64 Yol Bakım Onarım Müdürlüğü’ne makine mühendisi olarak atanmıştır. 2017 tarihi Aralık ayında Kapasite Yönetim Dairesine nakli yapıldı. Halen bu görevi sürdürüyor.

E-Posta: h.erenbeni@hotmail.com

\section{Beyanlar:}

Bu makalede bilimsel araştırma ve yayın etiğine uyulmuştur. 